\title{
DEU RUIM NA HASHTAG! BOTS E PANDEMIA DE FAKE NEWS EM TEMPOS DE COVID-19: O CASO \#FECHADOCOMBOLSO(L)NARO
}

Marcelle Medeiros Teixeira ${ }^{\mathrm{i}}$ Dilton Ribeiro Couto Junior ${ }^{\text {ii }}$

Resumo: O texto analisa o uso da hashtag \#FechadoComBolsolnaro, uma das mais disseminadas no Twitter em abril de 2020. Em meio a uma crise política no seu mandato presidencial, Jair Bolsonaro vira alvo de memes pelas/os internautas em resposta ao erro de digitação de seu sobrenome na hashtag, sugerindo o uso de bots (robôs) na tentativa de alavancar sua popularidade. Pesquisar fake news e bots mediante a utilização do método cartográfico convida a uma reflexão sobre o uso indiscriminado das redes para a formação da opinião pública, principalmente em tempos de pandemia, quando a população encontra-se mais vulnerável. Dessa forma, argumentamos que precisamos colocar em prática uma educação implicada no combate às fake news que comprometem a democracia brasileira.

Palavras-chave: Fake news; Bots; Pandemia; Democracia; Educação.

\section{THE HASHTAG WENT WRONG! BOTS AND FAKE NEWS PANDEMIC IN TIMES OF COVID-19: THE CASE \#FECHADOCOMBOLSO(L)NARO}

\begin{abstract}
The text analyzes the use of the hashtag \#FechadoComBolsolnaro (in English, \#ImWithYouBolsolnaro), one of the most popular hashtags posted on Twitter in April 2020. In the midst of a political crisis in his presidential term, Jair Bolsonaro has become the target of memes in response of his misspelled surname in the hashtag. This suggests the use of bots in an attempt to leverage the president's popularity. Researching fake news and bots using the cartographic method invites us to reflect on the indiscriminate use of social media and its effects on public opinion, mainly in pandemic times, during which society is more vulnerable. Thus, we argue that in order to preserve and maintain Brazilian democracy, we should implement educational practices that discourage and fight fake news.
\end{abstract}

Keywords: Fake news; Bots; Pandemic; Democracy; Education.

\section{“Quer que eu faça o quê?”: sobre as políticas de morte em plena pandemia}

Desde que foi decretada pandemia pelo novo coronavírus (SARS-CoV-2) em março de 2020 pela Organização Mundial da Saúde (OMS), o mundo vive em estado de alerta. Tosse, febre e insuficiência respiratória são alguns dos principais sintomas da COVID-19, doença causada pelo novo vírus e que vem sendo estudada por pesquisadoras/es de todo o mundo, que trabalham intensamente com seus pares na busca por medicamentos e pela tão esperada vacina capaz de fornecer anticorpos às pessoas (GARRIDO; GARRIDO, 2020). Enquanto aguardamos esperançosas/os por novos medicamentos e pela vacina, assistimos 
com muito temor ao aumento diário de pessoas infectadas em todo o mundo, trazendo como consequência drástica o colapso dos sistemas de saúde de alguns países.

Não somente isso, mas também o aumento de óbitos vem acarretando a necessidade de que não raramente contêineres ${ }^{\mathrm{iii}}$ refrigerados sejam colocados nas premissas de alguns hospitais para organizar os corpos dos falecidos. Ademais, tem ocorrido a escavação de valas coletivas $^{\text {iv }}$ para enterrar os mortos, que não param de chegar aos cemitérios. Muitos enterros estão sendo realizados no período da noite ${ }^{\mathrm{v}}$ porque os períodos matutinos e vespertinos são insuficientes para que todas as famílias das vítimas da COVID-19 se despeçam de seus entes queridos. Em algumas cidades, a falta de leitos nas unidades de terapia intensiva (UTIs) e de respiradores tem feito com que pessoas infectadas pela doença estejam na fila de espera para se internar.

No caso do Rio de Janeiro, existe um protocolo ${ }^{\text {vi }}$, ainda em fase de estudo pela Secretaria Estadual de Saúde em conjunto com o Conselho Regional de Medicina do Rio de Janeiro (Cremerj), que analisa quais pacientes infectadas/os com COVID-19 teriam prioridade na ocupação dos leitos de UTI. O protocolo é constituído por diversos quesitos envolvendo a atribuição de pontuação com base no funcionamento de determinados órgãos (entre eles, coração, rins e pulmões). Em caso de empate, a menor idade seria o fator decisivo para a conquista do leito. Essas são apenas algumas das situações cotidianas brasileiras que vimos acompanhando na grande mídia e que também repercutem nas principais redes sociais da internet, convidando-nos a uma reflexão sobre as decisões governamentais no enfrentamento à pandemia do novo coronavírus.

Diante do cenário de pandemia, questionamos: considerando que a insuficiência respiratória é um dos principais sintomas da doença (GARRIDO; GARRIDO, 2020), o que faz ser providenciado um contêiner refrigerado para guardar os mortos antes de leitos equipados com respiradores? Partimos do pressuposto de que a política pode ser considerada uma forma de guerra quando busca atingir um poder soberano que coloca em prática o direito de matar (MBEMBE, 2018). Afinal, “a expressão máxima da soberania reside, em grande medida, no poder e na capacidade de ditar quem pode viver e quem deve morrer" (MBEMBE, 2018 , p. 5). Dito isso, como pode uma pontuação ser decisiva na escolha de qual pessoa infectada pela COVID-19 deva (provavelmente) morrer para que um/a outro/a infectado/a tenha a chance de (possivelmente) sobreviver? Como pode um documento ditar quais vidas terão mais e menos pontos? Ademais, o que faz da pouca idade da/o jovem um atributo importante na escolha de quem tem "prioridade" de viver? E o que faz da idade avançada de uma pessoa um aspecto que a coloca em desvantagem para conseguir um leito de UTI? 
Não podemos negar que o protocolo não está buscando "salvar vidas", pois ele está colocando em prática uma política que age para "deixar morrer" outras tantas vidas cariocas devido à falta de infraestrutura do sistema de saúde do estado para atender todas as pessoas infectadas pela COVID-19. Isso tem nos colocado a refletir sobre a gravidade de nossa política contemporânea em tempos de pandemia. Essa situação nos traz como alerta a necessidade de questionar uma política que faz com que algumas vidas não sejam dignas de luto (BUTLER, 2015). Não podemos negar que essas vidas encontram-se permanentemente ameaçadas devido à falta de apoio social, enquadrando-se "em condições invisíveis em que parte das minorias [sociais] recorrentemente se encontra. As vidas precárias colocam-se no cotidiano de uma sociedade extremamente violenta e de estruturas macroeconômicas que definem nossa própria (des)humanidade" (COUTO JUNIOR et al., 2019, p. 1212). Enquanto os números (oficiais) de óbitos em abril de 2020 no Brasil já haviam ultrapassado o total de mortos pela COVID-19 na China, Bolsonaro questionava: "E daí? Lamento. Quer que eu faça

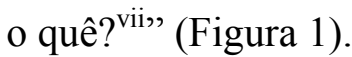

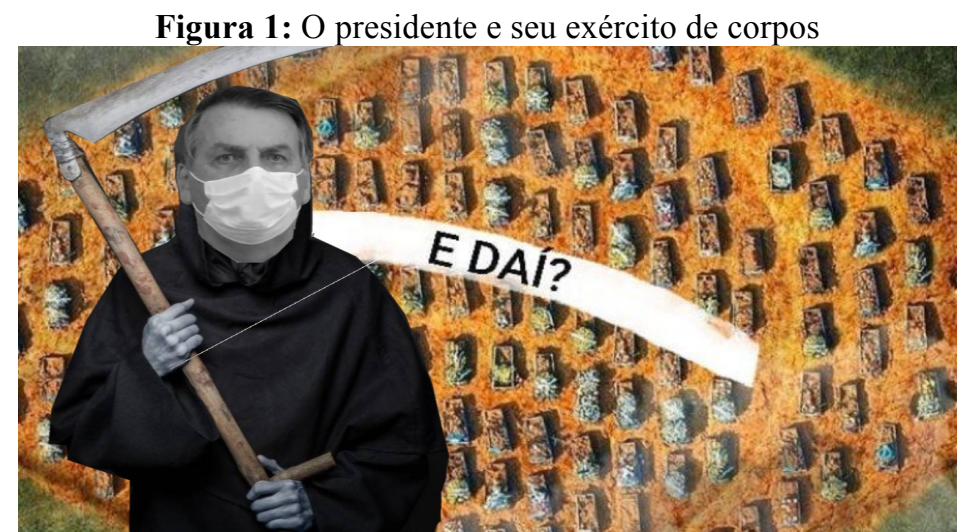

Fonte: Imagem capturada do Facebook no mês de maio de 2020.

Não seria demais supor que os contêineres e as valas coletivas fazem parte de um cenário de barbárie praticado por uma política da morte que não fornece uma rede de apoio suficiente à população, principalmente àquelas pessoas que integram os estratos socioeconômicos menos privilegiados. Na busca nem sempre bem-sucedida pelas máscaras de proteção e álcool em gel, conforme as recomendações da OMS, aquelas/es que estão em situação de maior vulnerabilidade social recorrem aos auxílios emergenciais (COUTO; COUTO; CRUZ, 2020). No Brasil, as pessoas que fazem parte do grupo de trabalhadoras/es informais, microempreendedoras/es individuais (MEI), autônomas/os e desempregadas/os, aglomeram-se na fila das casas lotéricas ou agências da Caixa Econômica Federal para sacar o auxílio do governo federal, no valor de $\mathrm{R} \$ 600,00$. 
Para sacar o auxílio, é preciso realizar um cadastro no site do governo ou via aplicativo do celular. Considerando que o Brasil enfrenta graves problemas quanto à democratização do acesso à internet (NOLASCO-SILVA, 2018), concordamos que as políticas da morte não são políticas que "deixam" morrer; pelo contrário, constituem-se em ações que provocam a morte com o uso de ações planejadas e sistemáticas (BENTO, 2018). Discutindo a situação de vulnerabilidade da população carcerária, Bento (2018, e185305) exemplifica algumas dessas ações praticadas pelas políticas da morte, denominadas pela autora como necrobiopoder: “comida estragada, não atendimento médico, superlotação das celas, pessoas presas sem acusação formal e sem sentença são algumas dessas técnicas. Não se trata de uma crise da população carcerária, ou uma falta de orçamento". Em tempos de pandemia, uma dessas ações do "fazer morrer" inclui a preocupação em como organizar os corpos das vítimas da COVID-19 por meio dos contêineres refrigerados, no lugar de focalizar esforços que assegurem maiores redes de apoio e proteção à população.

Não poderíamos deixar de destacar que também vivemos uma pandemia em um país cujo presidente é o militar reformado Jair Bolsonaro. Desde sua posse, em 2019, o governo Bolsonaro vem ocupando certo lugar de destaque na grande mídia nacional em função de seu envolvimento em diversos episódios considerados controversos, inclusive gerando repercussões internacionais negativas pela sua forma de praticar no país uma política considerada conservadora e irresponsável. Em tempos de pandemia, têm sido colocadas em prática ações governamentais que têm gerado descontentamentos, refletidos em atos como os panelaços, acompanhados de gritos que pedem a sua saída do poder. Esse descontentamento reflete a postura de um presidente que, em diversas ocasiões, "minimiza a gravidade da pandemia, debocha dos doentes e mortos, ironiza familiares que choram seus mortos, faz, apoia e ressalta discursos autoritários, agride profissionais de saúde, jornalistas e instituições” (COUTO; COUTO; CRUZ, 2020, p. 211).

Fornecemos antes um breve panorama da complexidade do cenário social vivido hoje no Brasil. Fruto de pesquisa de mestrado em andamento ${ }^{\text {viii }}$, este texto discute a propagação de fake news nas redes sociais durante a pandemia da COVID-19. Mais especificamente, nossa intenção é analisar a resposta das/os internautas diante do uso da hashtag \#FechadoComBolsolnaro. A hashtag tornou-se uma das mais disseminadas no mundo em abril de 2020 pelo provável uso de bots (robôs), responsáveis pela automatização do compartilhamento massivo de conteúdos por meio do uso da conta de usuárias/os. Em meio a uma crise política no seu mandato presidencial, Jair Bolsonaro acaba virando alvo de memes em função do erro de digitação de seu sobrenome na referida hashtag. Propagar uma suposta 
verdade por meio da disseminação massiva de tweets (publicações) com o objetivo de alavancar a popularidade do presidente convida a refletir sobre os perigos do uso indiscriminado das redes para a formação da opinião pública, principalmente em tempos de pandemia.

Apropriamo-nos dos conceitos de meme e fake news e operamos com a abordagem cartográfica de modo a acompanhar a produção de memes em resposta à hashtag \#FechadoComBolsolnaro. Compreendemos que "não há nenhuma novidade na tentativa de falsificação política através da distorção de fatos e informações" (GENESINI, 2018, p. 49); a novidade está justamente na intensa produção e no compartilhamento dessas narrativas falaciosas por meio das redes sociais digitais, cuja conexão livre entre pessoas e grupos em âmbito mundial potencializa a troca de (des)informação (SANTAELLA, 2019). Em decorrência dessa conexão em escala planetária, a disseminação de informações atinge alcance, eficácia e velocidade como jamais atingido anteriormente pelas mídias de massa, propiciando o aumento do número de fake news (BUCCI, 2018).

Com o objetivo de contestar as notícias falsas, temos acompanhado a produção de memes que fazem uso do humor para refletir sobre os acontecimentos cotidianos no âmbito da política brasileira. Pela sua facilidade de produção e propagação, os memes têm ganhado destaque nas redes digitais, visto que não exigem muitos recursos tecnológicos e experiência com programação para serem produzidos e compartilhados (SANTOS; COLACIQUE; CARVALHO, 2016). Aquelas/es que produzem memes em resposta às barbaridades de nosso tempo têm a oportunidade de resistir aos discursos hegemônicos, buscando nessas imagensdizeres modos de colocar em xeque determinadas ações e práticas culturais em prol de uma nova forma de ver/compreender o mundo (COUTO JUNIOR; POCAHY; CARVALHO, 2019).

A seguir discutimos nossa opção teórico-metodológica pelo método cartográfico na investigação de fake news e memes em tempos de pandemia. Posteriormente apresentamos e analisamos os memes em resposta à hashtag \#FechadoComBolsolnaro, que sugere o uso de bots na disseminação de uma possível falácia criada com o objetivo de aumentar a popularidade do presidente Bolsonaro em tempos de COVID-19. Por fim, na última parte do texto, concluímos o trabalho com alguns apontamentos acerca da importância de colocar em prática uma educação implicada no combate às fake news que comprometem a democracia brasileira. 


\section{Cartografando fake news e memes em tempos de pandemia}

Recentemente, com a revolução do processo de digitalização e a popularização de redes sociais como Facebook, Instagram, WhatsApp e Twitter, nossa forma de produzir, acessar, armazenar e compartilhar informação reconfigurou-se. Não podemos negar que "o aspecto mais espetacular da era digital está no poder dos dígitos para tratar toda informação, som, imagem, vídeo, texto, programas informáticos, com a mesma linguagem universal, uma espécie de esperanto das máquinas" (SANTAELLA, 2002, p. 54). A infraestrutura técnica do ciberespaço, a transmissão e o acesso de informações entre pessoas de todo mundo vêm desencadeando transformações na forma como interagimos com o outro (SANTAELLA, 2002); isso traz implicações para a pesquisa em Educação (COUTO JUNIOR et al., 2020).

Como profissionais do campo educacional, interessa-nos investigar a forma como as pessoas relacionam-se com os artefatos culturais com acesso à internet, buscando refletir sobre as dinâmicas comunicacionais em tempos de cibercultura, "que revelam a especificidade de uma época nitidamente marcada por práticas cotidianas exercidas cada vez mais através da mediação das tecnologias digitais em rede" (COUTO JUNIOR; SANTOS; VELLOSO, 2019, p. 1.130). O que vimos produzindo e compartilhando em tempos de COVID-19? O que nossas postagens narram sobre nossos cotidianos durante o isolamento físico? No contexto de uma pandemia de fake news, consideramos importante questionar as teorias conspiratórias (ALMEIDA; SANTOS, 2020), apropriando-nos de uma perspectiva teórico-metodológica que auxilie a analisar memes que narram a complexidade da política brasileira.

A opção teórico-metodológica pela cartografia digital para investigar os processos comunicacionais digitais ocorre pelo interesse em acompanhar os fluxos informacionais produzidos e compartilhados pelas/os internautas. Não buscamos trilhar um caminho a priori em nossa investigação, uma vez que entendemos que não se trata de estabelecer uma linearidade com o objetivo de atingir um fim (KASTRUP, 2015; PRADO FILHO; TETI, 2018). Dessa forma, "pensamos-praticamos a cartografia enquanto método, não no sentido de procedimentos a serem seguidos, um passo a passo fechado em si, mas como modos de problematização de mundos, a partir de um olhar-sentir outro a vida cotidiana" (CARVALHO; POCAHY, 2020, p. 96). Como praticantes culturais imersas/os nas dinâmicas ciberculturais, vimos acompanhando processos, participando de interações com outras/os usuárias/os geograficamente dispersas/os que também têm muito a nos dizer. Discordamos da 
perspectiva de que coletamos dados, entendendo que tecemos reflexões com base em acontecimentos cotidianos (KASTRUP, 2015).

A cartografia abre espaço para um movimento contínuo na forma de se fazer pesquisa, cujo foco encontra-se voltado para o caminhar, para o acompanhamento dos processos (POZZANA; KASTRUP, 2015; PRADO FILHO; TETI, 2018). A imersão e implicação com as questões sociais mediadas pelo digital em rede são alguns dos atributos que consideramos imprescindíveis para o/a pesquisador/a que adota o método cartográfico na pesquisa online (CARVALHO; POCAHY, 2020). Entendemos a cartografia como uma oportunidade de nos colocarmos abertas/os ao mundo, acompanhando as transformações sociais engendradas pelas dinâmicas da rede, questionando a produção e o compartilhamento de postagens online que podem nos oferecer pistas e entradas de problematização que proporcionem reflexões importantes para um melhor entendimento de nosso presente.

Concordamos que o método cartográfico pode auxiliar no acompanhamento dos impactos sociais do novo coronavírus no contexto de uma pandemia de fake news que dizem respeito à (im)popularidade do presidente brasileiro. Cartografamos para intervir no mundo, percorrendo um processo que nos afeta e que nos convida a buscar outras formas de verhabitar o mundo (POCAHY; SILVA; DOURADO, 2020). Diante disso, colocamo-nos atentos aos diferentes memes produzidos/compartilhados nas diferentes redes sociais da internet, focalizando nosso olhar sobre aqueles que se dedicam a expor possíveis fake news disseminadas por bots em tempos de COVID-19.

A dinamicidade dos processos comunicacionais digitais de produzir-compartilhar ideias na/em rede faz da internet um espaço fecundo para a produção de memes. Memes são arquivos envolvendo imagens e dizeres que expressam ideias responsáveis pelo deslocamento de "significados que são difundidos de um indivíduo a outro através de dinâmicas replicadas, mixadas e compiladas e recompiladas que adaptam novas perspectivas ao seu contexto original" (ALMEIDA; SANTOS, 2020, p. 178). Embora autorais, os memes rompem com a perspectiva tradicional de autoria, uma vez que são arquivos que circulam de forma dinâmica pela infraestrutura do ciberespaço, sendo constantemente (re)editados pelas/os internautas com a intenção de potencializar/atualizar/ressignificar a ideia original, adaptando-a a novos contextos socioculturais.

Os memes apresentados e analisados a seguir foram capturados entre os meses de fevereiro e maio de 2020 nas redes sociais Twitter e Facebook. Essas imagens revelam a crescente insatisfação das/os brasileiras/os diante de como o Governo Federal vem lidando com a COVID-19 no país; algumas delas também denunciam a hashtag 
\#FechadoComBolsolnaro, sugerindo o uso de bots como tentativa de forjar a popularidade do presidente brasileiro em tempos de pandemia pelo novo coronavírus.

\section{Sobre (im)popularidade em tempos de pandemia: o caso \#FechadoComBolsolnaro}

Em meio à pandemia da COVID-19, o presidente Jair Bolsonaro tornou-se alvo de críticas nas redes sociais digitais devido aos seus pronunciamentos e suas tomadas de decisão contrários às orientações da OMS. No dia 24 de abril de 2020, o anúncio da demissão de Sérgio Moro, até então ministro da Justiça e Segurança Pública, intensificou o cenário e configurou a mais grave crise política do mandato presidencial de Bolsonaro até aquele momento. $\mathrm{O}$ ex-juiz deixou o cargo alegando que Bolsonaro buscava interferir politicamente na Polícia Federal $(\mathrm{PF})^{\mathrm{ix}}$ em benefício próprio e de seus filhos ao decidir demitir Mauricio Valeixo, diretor-geral da instituição.

A partir desse episódio, identificamos o aumento de hashtags compartilhadas a favor de Bolsonaro nas redes, principalmente no Twitter. No dia 27 de abril de 2020, a hashtag \#FechadoComBolsolnaro viralizou, chegando a ocupar o primeiro lugar no Brasil e o décimo sexto lugar no rank mundial dos Trending Topics ou "Assuntos do Momento", aba destinada aos temas mais comentados e compartilhados. No entanto, chama atenção a grafia errada do sobrenome do presidente, que recebe uma letra "L" a mais e vira alvo de memes (Figuras 2, 3 e 4). De acordo com o website Getdaytrends, por volta das $20 \mathrm{~h}$ do dia 27 de abril de 2020 havia mais de 78 mil $^{\mathrm{x}}$ tweets utilizando a hashtag \#FechadoComBolsolnaro.

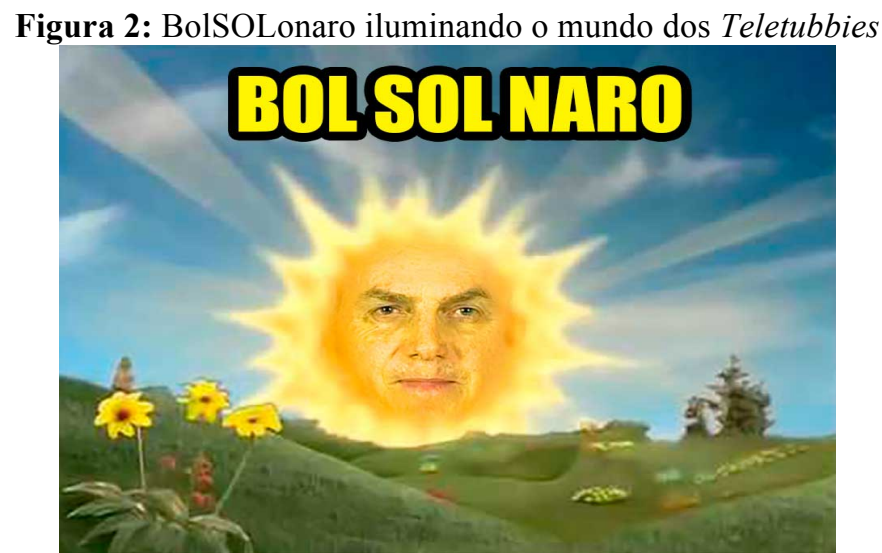

Fonte: Imagem capturada do Facebook no mês de março de 2020.

A viralização de um material de apoio político cuja grafia é incorreta levanta suspeitas quanto à utilização de bots, pois trata-se de um erro grave. De acordo com Michalski e Paula (2019, p. 9, grifo nosso), os bots se passam por usuárias/os comuns ao imitarem comportamentos humanos, "interagindo com outros utilizadores da rede em debates, 
publicando conteúdo artificialmente, utilizando hashtags em apoio ou ataque a determinado indivíduo, disseminando conteúdo falso e manipulando os Trending Topics". A suspeita é levantada pelas/os internautas, que passam a utilizar os memes como estratégia para desestabilizar a suposta popularidade do presidente nas redes, denunciando o provável uso dos bots com fins políticos.

Essa suspeita caminha ao encontro dos estudos de Silveira (2019, p. 33), que suscita o debate sobre o uso de bots nas redes sociais, apontando para a gravidade da reprodução de mensagens em larga escala "com o objetivo de criar a impressão de que muitas pessoas seguem e replicam uma dada liderança política". Sob essa perspectiva, a disseminação da hashtag \#FechadoComBolsolnaro nos faz refletir sobre alguns fatores que sugerem o acionamento de bots. Avaliando a crise política governamental, reconhecemos que os bots de disseminação de apoio encontram-se diretamente relacionados à ilusão de que determinada opinião é bem aceita na rede, impulsionando outras/os internautas a se reconhecerem naquele discurso e a propagá-lo (MICHALSKI; PAULA, 2019). Dessa forma, a popularização da hashtag atrairia visibilidade positiva ao presidente, demonstrando em números a parcela da sociedade que continua acreditando e confiando no seu trabalho, mesmo após as acusações do ex-ministro.

Figura 3: Robô do filme Exterminador do Futuro também \#FechadoComBolsolnaro

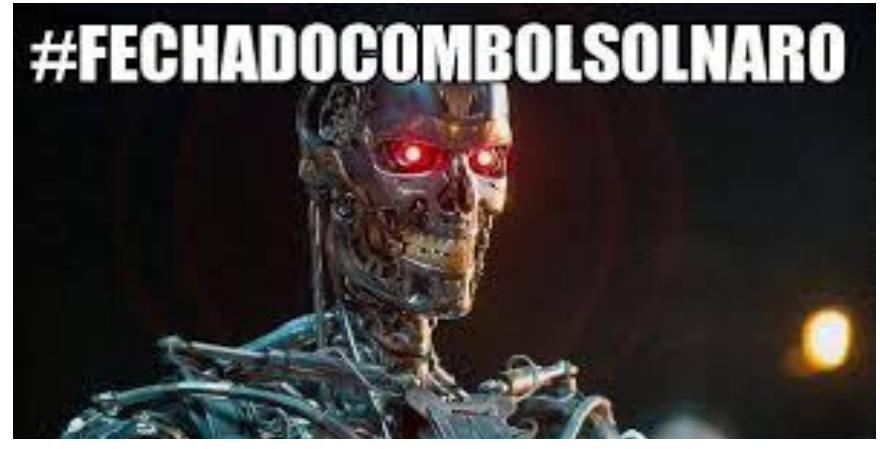

Fonte: Imagem capturada do Facebook no mês de maio de 2020.

É importante frisar que não é a primeira vez que uma hashtag em prol de Bolsonaro ocupa os primeiros lugares no Trending Topics do Twitter e levanta suspeitas por parte das/os internautas sobre o uso de bots. Um desses episódios teve início no dia 7 de março de 2020, quando o presidente se declarou ${ }^{\mathrm{xi}}$ a favor da manifestação marcada por apoiadoras/es para o dia 15 de março de 2020, momento em que 95 países do mundo somavam mais de cem mil infectadas/os e três mil mortes pelo novo coronavírus xii. A hashtag \#bolsonaroday, disseminada massivamente na véspera da manifestação do dia 15 e em plena pandemia da COVID-19 no Brasil, virou alvo de questionamentos. Com mais de 1 milhão e 200 mil 
menções nos tweets, a hashtag liderou os Trending Topics e converteu-se em objeto de estudo que buscou analisar a automatização de perfis no Twitter por meio de inteligência artificial e mais de mil parâmetros selecionados, garantindo alcançar em $80 \%$ a precisão dos dados (KALIL; SANTINI, 2020). O resultado da pesquisa apontou que os perfis automatizados foram capazes de gerar, no dia 15 de março de 2020, aproximadamente 55\% do tráfego da rede social com a hashtag \#bolsonaroday (KALIL; SANTINI, 2020), o que sugere outra tentativa estratégica do uso da rede como forma de atrair apoio político.

Como pesquisadoras/es do campo educacional interessados na forma como os sujeitos vêm se mobilizando politicamente por meio das redes sociais, preocupamo-nos diante do fato de que tem se tornado cada vez mais comum a "propagação de perfis fakes, bots e notícias falsas que disseminavam ódio, desinformação e confusão em busca de convocar, nesses espaços, simpatizantes dispostos a atuar nas trincheiras da mais nova frente de combate da política brasileira" (ALMEIDA; SANTOS, 2020, p. 184, grifo dos autores). Compreendendo nosso papel político e social, procuramos questionar os acontecimentos cotidianos que atravessam nossas próprias experiências nas redes digitais, fazendo de nossos perfis um espaço importante para fomentar debates políticos com outras/os professoras/es e estudantes.

Figura 4: Exército de robôs pró-Bolsonaro

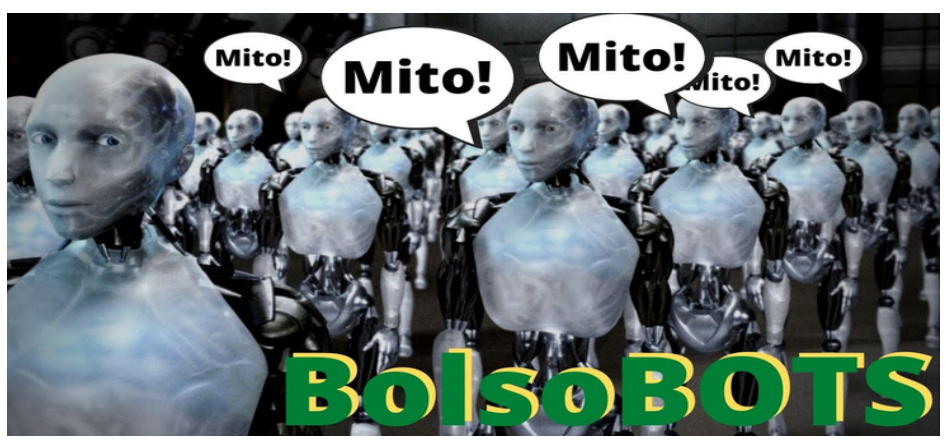

Fonte: Imagem capturada do Facebook no mês de abril de 2020.

Concordamos com Santos e Weber (2013, p. 300), para quem o digital em rede vem alterando "as formas de comunicação, produção, criação e circulação de informação, redesenhando uma configuração social e cultural". Dito isso, embora a internet nos permita emitir-trocar em rede, isso não significa que as interações entre os sujeitos sejam sempre harmônicas, pois comumente há divergência de ideias-reflexões. Nesse contexto, preocupanos a guerra de narrativas produzidas e disseminadas na rede, em que a avalanche de desinformação requer uma análise cuidadosa (ALMEIDA; SANTOS, 2020). Em tempos de pandemia de fake news, inquieta-nos a quantidade de (des)informações que vêm sendo 
produzidas nas redes sociais, impulsionadas muitas vezes pelo uso dos bots, que dão visibilidade a um suposto apoio ao "mito"xiii Bolsonaro (Figura 4). A produção e a disseminação de desinformação nas redes vêm sendo utilizadas como estratégia política do presidente desde o período eleitoral, com as redes se constituindo como um meio de comunicação importante do governo Bolsonaro (SILVEIRA, 2019).

Por estarmos imersas/os na era da pós-verdade, reforçamos que os princípios que despertam o desejo pelo compartilhamento passam a estar diretamente relacionados a emoções, sejam elas positivas ou negativas (BUCCI, 2018). Como consequência direta, temos a "disseminação de pós-verdade, cujo poder de proliferação aumenta em situações ultrapartidárias, quando a veracidade ou falsidade da informação é o que menos importa" (SANTAELLA, 2019, p. 52). Sob essa perspectiva, problematizamos o compartilhamento leviano e a velocidade da ação impensada às/aos internautas na rede, que colocam suas emoções à frente do compromisso ético com a verdade, disseminando conteúdos que muitas vezes buscam reiterar pontos de vista, independentemente da veracidade das informações publicizadas (SANTAELLA, 2019).

Os memes que circulam na rede e aqueles que se encontram incorporados a este texto convidam a olhar para a complexidade do contexto político brasileiro em 2020. Vivemos hoje uma crise social instaurada pela pandemia do novo coronavírus, ao mesmo tempo que assistimos à diminuição da popularidade do governo Bolsonaro. Apesar de uma fala convicta sobre a capacidade de lutar contra a COVID-19, as colocações do presidente comumente desalinham-se com as orientações da própria OMS: “Alguns vão morrer? Vão, ué, lamento. Essa é a vida"xiv " "Não vai ser uma gripezinha que vai me derrubar"xv" "Outras gripes mataram mais do que essa"xvi , 'Não podemos entrar 'numa' neurose, como se fosse o fim do mundo"xvii ou "“Tá' sendo superdimensionado o poder destruidor desse vírus" "xviii. Diante dessas afirmações, cabe frisar que somos estimuladas/os a nos tornar potenciais emissoras/es de fake news "quando o próprio governo contraria e desmoraliza instituições confiáveis e passa a propagar desinformação e embasar discursos baseados em alucinações ou não fazendo a estes nenhum tipo de contra-ação" (ALMEIDA; SANTOS, 2020, p. 186). 
Figura 5: Sobre as dificuldades de colocar a máscara durante pronunciamento ao vivo

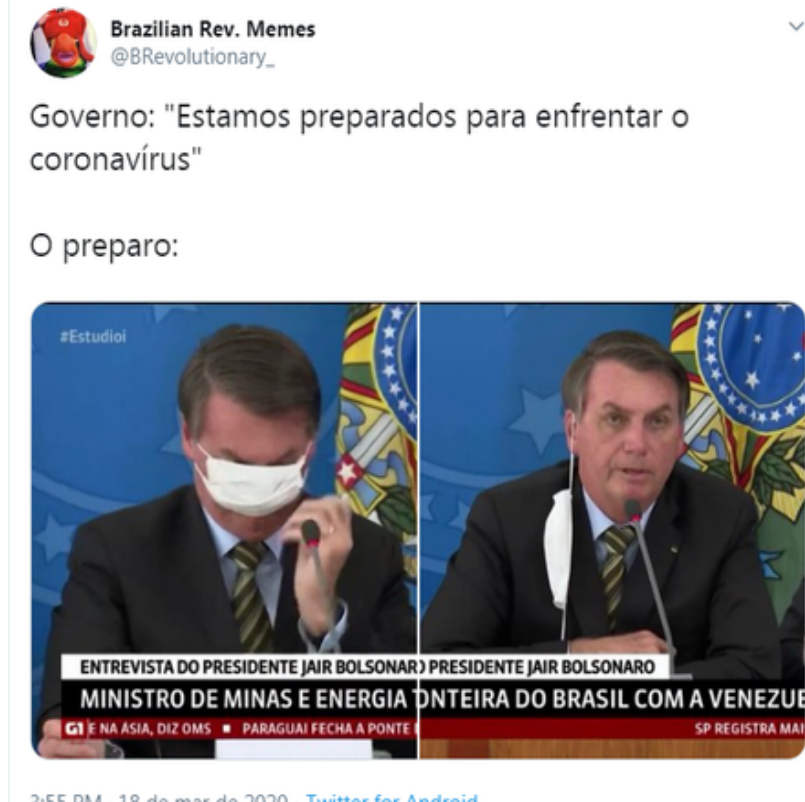

3:55 PM - 18 de mar de 2020 - Twitter for Android

Fonte: Imagem capturada do Twitter no mês de março de 2020.

Quando a própria máscara de proteção recomendada pela OMS para evitar a contaminação pelo novo coronavírus é manuseada incorretamente durante o discurso presidencial, conforme a crítica feita pelo meme mostrado na Figura 5, o que podemos esperar das ações do Governo Federal voltadas para o cuidado com a saúde da população em tempos de pandemia? Reforçamos que nossa escrita é política; portanto, não conseguimos nos dissociar do contexto em que estamos atualmente inseridas/os, tampouco ignorar a forma como o novo coronavírus tem sido tratado pelo presidente brasileiro. As estratégias propostas pelo governo Bolsonaro para conter a velocidade do contágio da COVID-19 entraram em divergência não só com as orientações da OMS, mas também com o próprio Henrique Mandetta, hoje ex-ministro da Saúde no Brasil. O efeito dessa divergência resultou na demissão de Mandetta em 16 de abril de $2020^{\text {xix }}$, sendo substituído pelo oncologista Nelson Teich, que pediu demissão do cargo em 15 de maio de $2020^{\mathrm{xx}}$, antes mesmo de completar um mês, justificado pelo desalinhamento de informações e discordâncias com as ações do presidente. Ao final da primeira semana de junho de 2020, período de finalização desse texto, o Brasil permanecia há mais de 20 dias sem um ministro titular da Saúde.

Diante desse cenário, frente ao compartilhamento da hashtag \#FechadoComBolsolnaro, concordamos com Santaella (2019, p. 27) sobre a importância de planejar "ações criativas como antídotos à propaganda enganadora, às falas de ódio, aos conteúdos preconceituosos e às notícias falsas". Nesse sentido, procuramos neste texto analisar como os memes refletem o engajamento da sociedade civil na rede como forma de 
questionar a pandemia de fake news disseminadas por bots. Somando-se a isso, o discurso presidencial vem forjando uma realidade baseada em "um processo de suspensão do debate público e uma destruição da racionalidade e sua substituição pelo confronto dogmático, semelhante às guerras religiosas" (SILVEIRA, 2019, p. 34). Desse modo, consideramos cada vez mais preocupante o agir político de Bolsonaro em plena pandemia da COVID-19, pois suas políticas de enfrentamento ao novo coronavírus têm partido de convicções pessoais que colocam em xeque as orientações da própria OMS. Como resultado, a produção e a reiteração de um discurso que minimiza/banaliza o novo coronavírus são evidentes quando "sai às ruas sem máscara ou com máscara no pescoço, toca, abraça, beija e faz selfies com apoiadores enquanto tosse e fala de perto às pessoas que correm para vê-lo, apoiá-lo e segui-lo" (COUTO; COUTO; CRUZ, 2020, p. 211, grifo dos autores).

Diante do exposto, nossas inquietações de pesquisa encontram-se alinhadas com uma perspectiva que reconhece o quanto determinadas políticas de morte (MBEMBE, 2018) colocam em prática um conjunto de ações que vulnerabilizam vidas, fazendo com que muitas delas não sejam dignas de luto (BUTLER, 2015). O cenário de barbárie instaurado pelas decisões governamentais brasileiras em plena pandemia nos faz questionar até quando estaremos dispostas/os a tolerar o massacre social que vivemos hoje pela falta de políticas de enfrentamento à COVID-19. Longe de concordar que essas mortes sejam simplesmente provocadas pela nova doença, consideramos que essas mortes vêm sendo provocadas por políticas que matam (MBEMBE, 2018). Reiteramos que essas políticas, no lugar de focar na construção de hospitais de campanha para atender as pessoas infectadas pela COVID-19, cavam valas coletivas e providenciam contêineres para armazenar os corpos das vítimas.

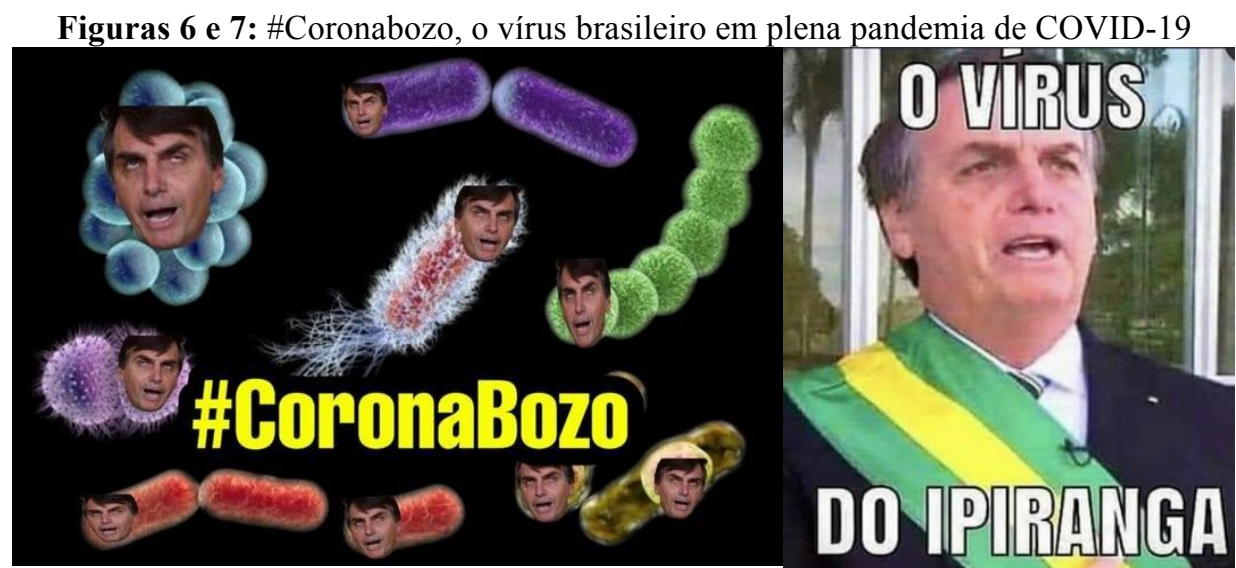

Fonte: Imagens capturadas do Facebook respectivamente nos meses de fevereiro e março de 2020.

Sobre as políticas do "deixar morrer" (MBEMBE, 2018): o novo coronavírus não é o único responsável pela morte de milhares de pessoas no Brasil em 2020. Alguns memes 
evidenciam essa crítica ao sugerir que a maior ameaça em tempos de pandemia é o vírus que se instala no gabinete presidencial. Após ser "diagnosticado" com aumento da impopularidade, o \#CoronaBozo apropria-se das redes sociais para disseminar fake news, possivelmente fazendo dos bots um de seus grandes aliados no Brasil.

\section{Enfrentando o \#CoronaBozo em plena pandemia da COVID-19: educação e democracia em debate}

Partimos do pressuposto de que as mentiras no campo político sempre existiram; no entanto, agora estamos diante de sua disseminação em massa viabilizada pelo potencial da rede (BUCCI, 2018; SANTAELLA, 2019). Diante desse cenário, analisamos o possível uso de bots na hashtag \#FechadosComBolsolnaro e refletimos sobre sua grave ameaça à democracia caso tenha sido articulada com o objetivo de ampliar a popularidade do presidente. Como pesquisadores do campo educacional implicados com os estudos em cibercultura, enxergamos a rede como um espaço potente para fomentar debates políticos e promover a articulação de movimentos de resistência orquestrados por meio da internet (COUTO JUNIOR; VELLOSO; SANTOS, 2020; COUTO JUNIOR et al., 2019). Uma das estratégias políticas de resistência no enfrentamento à pandemia de fake news em tempos de COVID-19 são os memes, conforme analisados neste texto.

Com a emergência das práticas sociais na cibercultura, saímos da posição de meras/os receptoras/es de informações produzidas pelas grandes empresas de comunicação e nos tornamos produtoras/es de informação para a rede. Isso é o que mostra Lemos (2010) a partir da "liberação da palavra", um dos princípios da cibercultura. No momento em que os sujeitos passam a produzir e distribuir informações de forma mais horizontalizada, "cria-se uma potência política, social e cultural: a potência da reconfiguração e da transformação" (LEMOS, 2010, p. 27). Desse modo, o ciberespaço torna-se um ambiente de pesquisa promissor ao proporcionar maior liberdade de expressão pela infraestrutura técnica da internet (COUTO JUNIOR et al., 2020).

A liberdade de expressão, uma das características do regime democrático, é considerada um direito humano universal, previsto no Artigo 19 da Declaração Universal dos Direitos Humanos (ONU, 1948). Intelectual, científica, artística, religiosa, filosófica ou de comunicação, a liberdade de expressão é condição fundamental para o pleno exercício da cidadania; por isso precisamos assegurar essa prática em prol da construção de uma sociedade com maiores margens de liberdade. Em meio à uma pandemia de fake news de cunho político, 
questionamos a falta de um compromisso ético com a verdade, o que traz graves riscos à nossa democracia.

Poder transpor em palavras ou imagens tudo aquilo que caminha de encontro às convicções pessoais pode ser considerado uma espécie de mola propulsora para a manipulação dos fatos. Sob esse raciocínio, argumentamos que compartilhar informações falsas e justificar com a liberdade de expressão pode colocar em xeque os princípios democráticos. Dessa forma, questionamos: quais os desafios necessários à construção de um olhar mais crítico que sirva para colocar em xeque as fake news? Como o espaço da rede pode auxiliar na constituição de novas estratégias de resistência às fake news? Até quando estaremos dispostas/os a tolerar políticas de morte em pleno regime democrático? São muitos os questionamentos que nos guiam ao longo do percurso investigativo da pesquisa e que nos inquietam não só como pesquisadores, mas como cidadã/ãos. Uma coisa é certa: devemos enfrentar essa política de morte com o objetivo de promover o bem-estar de todas/as, educando "democraticamente para as liberdades" (COUTO; COUTO; CRUZ, 2020, p. 212).

Mostra-se necessário colocar em prática uma educação que vise ampliar nossas margens de liberdade, na medida em que o perigo das fake news recai justamente sobre as/os internautas que tendem a não questionar as informações que se encontram alinhadas com suas formas de ver/entender o mundo. Acreditar veemente em tudo o que é disseminado na rede significa que perdemos uma oportunidade formativa importante de conhecer o contexto de produção de determinada informação. Apostamos em uma educação em rede e para as redes com o objetivo de confrontar informações e notícias falsas a partir da consulta de dados, registros e pesquisas disponíveis. Com base nessa perspectiva, almejamos continuar exercitando uma postura crítica de contra-atacar os discursos por detrás das fake news, fazendo da educação um ato "cada vez mais político, ideológico e emancipatório" (ALMEIDA; SANTOS, 2020, p. 185).

A implementação de uma formação crítica funcionaria como um antídoto para o combate às fake news. Na prática, sugerimos o fact-checking, ou seja, a checagem de notícias e fatos, mesmo tendo ciência de sua complexidade, justificada pela quantidade exponencial de informações compartilhadas a todo instante nas redes (GENESINI, 2018). Dessa forma, para além de educar e formar cidadãs/ãos implicadas/os com o compromisso com a verdade, concordamos com Almeida e Santos (2020), para quem os responsáveis por essa implementação serão propagadoras/es de dias melhores, de esperança.

Embora os memes também sejam veículos que propagam fake news e difundem de forma massiva discursos de ódio e preconceitos diversos (NOLASCO-SILVA; SOARES; 
BIANCO, 2019), os memes apresentados neste trabalho constituem-se como estratégias de enfrentamento às decisões governamentais de Bolsonaro. A potência dessas imagens-dizeres sugere o uso de bots na hashtag \#FechadosComBolsolnaro, ao mesmo tempo que denuncia as políticas de morte de um governo que, em plena pandemia, carece de medidas eficazes de enfrentamento ao novo coronavírus. O próprio meme do \#CoronaBozo reitera a preocupação de muitas/os internautas com o atual governo, argumentando que o ser vivo mais perigoso para o Brasil durante o período da pandemia tem sido o próprio presidente. Caminhamos na mesma linha de pensamento de Couto, Couto e Cruz (2020, p. 212) e concordamos que "devemos estar atentos e preocupados com as novas formas de políticos ditatoriais que se aproveitam da pandemia para desenvolver [...] restrições de liberdade e perdas de direitos sociais, profissionais e pessoais que comprometem a cidadania e a democracia".

O potencial da infesaestrutura técnica da rede para disseminar (des)informações revela a complexidade de investigarmos os efeitos do uso de bots na propagação de fake news com a intenção de enfraquecer os discursos por detrás delas. Consideramos, assim, o poder da educação como estratégia importante para o "desenvolvimento de habilidades que tornam o usuário confiante na tarefa de interrogar sobre a precisão de uma informação e desafiar representações injustas, visões extremistas, violências simbólicas e brincadeiras ofensivas" (SANTAELLA, 2019, p. 28).

Não podemos ser ingênuos e acreditar que vivenciamos/experimentamos "uma ciberdemocracia de trocas livres e igualitárias. O isolamento social criativo é para poucos, para os que têm moradias adequadas e dignas, em espaços bem urbanizados, com renda suficiente e conexão de internet estável e veloz" (COUTO; COUTO; CRUZ, 2010, p. 210). O novo coronavírus vem escancarando as desigualdades sociais no Brasil, alertando para a necessidade de que possamos repensar a sociedade que temos hoje, questionando as decisões políticas em tempos de COVID-19 e seus efeitos sobre o bem-estar das pessoas. Não temos tido o tempo que gostaríamos para chorar pelas mortes daquelas/es que adoeceram por causa do novo vírus, porque temos buscado agir contra um fazer político que coloca em risco a vida de toda a população brasileira.

No momento de finalização da escrita deste texto, o Brasil apresenta mais de 35 mil mortes pelo novo coronavírus (sabemos que há subnotificação, ou seja, o número é muito maior). A hashtag \#FechadosComBolsolnaro fornece indícios de que a pandemia não é prioridade em uma agenda política que se encontra voltada principalmente para a manutenção da (suposta) popularidade do presidente. Não é demais supor que a hashtag sugere o uso de bots, tanto pela ortografia incorreta do sobrenome do presidente quanto pelo 
compartilhamento massivo no Twitter em abril de 2020. Face às reflexões, buscamos questionar a política conservadora de Bolsonaro, preocupando-nos em alertar para o quanto nossa democracia hoje vem sofrendo ataques incessantes de um governo que faz das redes sociais grandes aliadas.

Fazemos nossas as palavras de Silveira (2019, p. 44), que reitera a necessidade de "recolocar a democracia no coração das sociedades". Dessa forma, entendemos que precisamos continuar ampliando o debate, dentro e fora da universidade, sobre a importância de combater as fake news que circulam livremente pelas diversas redes sociais e que comprometem a democracia brasileira. Para complexificar ainda mais o cenário que vivemos hoje, a pandemia de fake news continua alimentando as redes sociais em tempos de COVID19. Para nossa sorte, a gente desconfia da popularidade presidencial quando dá ruim na hashtag.

\section{Referências}

ALMEIDA, W.; SANTOS, E. De memes a fake news: desafios de uma pesquisa-formação na cibercultura. Revista Educação em Foco, Juiz de Fora, v. 25, n. 1, p. 173-196, jan./abr. 2020. Disponível em: $<$ https://bit.ly/35womZD $>$. Acesso em: 16 jun. 2020.

BENTO, B. Necrobiopoder: quem pode habitar o Estado-nação? Cadernos Pagu, Campinas, n. 53, e185305, 2018. Disponível em: $<$ https://bit.ly/2yB4pVv>. Acesso em: 7 maio 2020.

BUCCI, E. Pós-política e corrosão da verdade. Revista USP, São Paulo, n. 116, p. 19-30, jan./fev./mar. 2018. Disponível em: <https://bit.ly/2Olatpr >. Acesso em: 19 jan. 2020.

BUTLER, J. Quadros de guerra: quando a vida é passível de luto? Tradução de Sérgio Lamarão e Arnaldo Marques da Cunha. Rio de Janeiro: Civilização Brasileira, 2015.

CARVALHO; F. S. P.; POCAHY, F. Cartografias ciberculturais da formação docente: experimentações autorais na disciplina de educação estética. Revista Ciências Humanas,

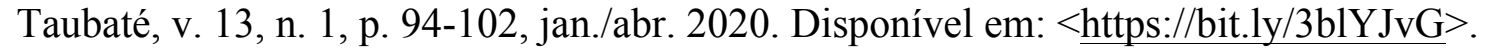
Acesso em: 10 maio 2020.

COUTO JUNIOR, D. R.; SANTOS, R.; VELLOSO, L. Rede social e comunicação ubíqua: o que podemos aprender com Black Mirror? Revista Diálogo Educacional, Curitiba, v. 19, n. 62, p. 1128-1146, jul./set. 2019. Disponível em: $<$ https://bit.ly/35HXqVs $>$. Acesso em: 27 nov. 2019.

COUTO JUNIOR, D. R.; VELLOSO, L.; SANTOS, R. Os movimentos ciberativistas de (re)existência nas redes sociais e suas implicações para a educação. Revista Teias, Rio de Janeiro, v. 21, n. 60, p. 91-108, jan./mar. 2020. Disponível em: $<$ https://bit.ly/2weX6Bj>. Acesso em: 1 mar. 2020. 
COUTO JUNIOR, D. R.; POCAHY, F.; CARVALHO; F. S. P. Ensinar-aprender com os memes: quando as estratégias de subversão e resistência viralizam na internet. Periferia, Rio de Janeiro, v. 11, n. 2, p. 17-38, maio/ago. 2019. Disponível em: <https://bit.ly/2EsoMEd $>$. Acesso em: 22 maio 2019.

COUTO JUNIOR, D. R. et al. Do face a face às dinâmicas comunicacionais em/na rede: a conversa online como procedimento metodológico da pesquisa em educação. Revista Educação em Foco, Juiz de Fora, v. 25, n. 1, p. 109-130, jan./abr. 2020. Disponível em: $<$ https://bit.ly/35womZD $>$. Acesso em: 16 jun. 2020.

COUTO JUNIOR, D. R. et al. Jovens em estado de alerta no Facebook: diálogos tecidos em/na rede como estratégia de (re-)existência à regulação das vidas precarizadas. Práxis Educativa, Ponta Grossa, v. 14, n. 3, p. 1210-1229, set./dez. 2019. Disponível em: $<$ https://bit.ly/2oqpqfW $>$. Acesso em: 2 out. 2019.

COUTO, E.; COUTO, E; S.; CRUZ, I. M. P. \#Fiqueemcasa: educação na pandemia da COVID-19. Interfaces Científicas - Educação, Aracaju, v. 8, n. 3, p. 200-217, 2020.

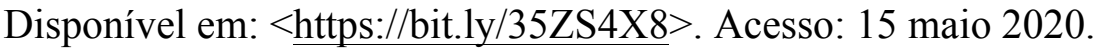

GARRIDO, R. G.; GARRIDO, F. S. R. G. COVID-19: um panorama com ênfase em medidas restritivas de contato interpessoal. Interfaces Científicas - Saúde e Ambiente, Aracaju, v. 8, n. 2, p. 127-141, 2020. Disponível em: <https://bit.ly/3cudw8I >. Acesso em: 20 abr. 2020.

GENESINI, S. A pós-verdade é uma notícia falsa. Revista USP, São Paulo, n. 116, p. 45-58, jan/mar. 2018. Disponível em: <https://is.gd/UF5CSV>. Acesso em: 19 abr. 2020.

KALIL, I.; SANTINI, R. M. Coronavírus, Pandemia, Infodemia e Política. Relatório de pesquisa. São Paulo / Rio de Janeiro: FESPSP / UFRJ, 2020, 21p. Disponível em: $<$ https://is.gd/hP6JZV $>$. Acesso em: 17 maio 2020.

KASTRUP, V. O funcionamento da atenção no trabalho do cartógrafo. In: PASSOS, E.; KASTRUP, V.; ESCÓSSIA, L. (Orgs.). Pistas do método da cartografia: pesquisaintervenção e produção de subjetividade. Porto Alegre: Sulina, 2015, p. 32-51.

LEMOS, A. Os sentidos da tecnologia: cibercultura e ciberdemocracia. In: LEMOS, A.; LÉVY, P. O futuro da internet: em direção a uma ciberdemocracia planetária. São Paulo: Paulus, 2010, p. 21-31.

MBEMBE, A. Necropolítica: biopoder, soberania, estado de exceção, política da morte. Tradução de Renata Santini. São Paulo: n-1 Edições, 2018.

MICHALSKI, R.; PAULA, L. T. Os bots de disseminação de informação na conjuntura das campanhas presidenciais de 2018 no Brasil. Múltiplos Olhares em Ciência da Informação, Minas Gerais, v. 9, n. 1, p. 1-16, jul. 2019. Disponível em: $<$ https://is.gd/ehQnJ3>. Acesso em: 5 jun. 2020.

NOLASCO-SILVA, L. "Os olhos tristes da fita rodando no gravador": as tecnologias educacionais como artesanias docentesdiscentes. 2018. 205f. Tese (Doutorado em Educação) - Faculdade de Educação, Universidade do Estado do Rio de Janeiro, Rio de Janeiro, 2018. 
NOLASCO-SILVA, L.; SOARES, M. C. S.; BIANCO, V. L. Os memes e o golpe. Periferia, Rio de Janeiro, v. 11, n. 2, p. 111-130, maio/ago. 2019. Disponível em:

$<$ https://bit.ly/2kW2Pqq $>$. Acesso em: 20 set. 2019.

ORGANIZAÇÃO DAS NAÇÕES UNIDAS (ONU). Declaração universal dos direitos

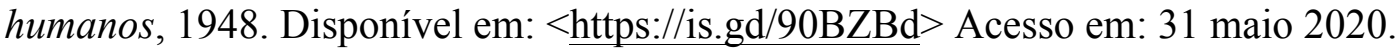

POCAHY, F.; SILVA, A. L. G.; DOURADO, E. O. C. A cartografia como pesquisain(ter)venção do/no presente: modos de/para pensar-fazer a formação docente. Revista Ciências Humanas, Taubaté, v. 13, n. 1, p. 5-10, jan./abr. 2020. Disponível em: $<$ https://bit.ly/3fqLU6O $>$. Acesso em: 6 maio 2020.

BARROS, L. P.; KASTRUP, V. Cartografar é acompanhar processos. In: PASSOS, E.; KASTRUP, V.; ESCÓSSIA, L. (Orgs.). Pistas do método da cartografia: pesquisaintervenção e produção de subjetividade. Porto Alegre: Sulina, 2015, p. 52-75.

PRADO FILHO, K.; TETI, M. M. A cartografia como método para as ciências humanas e sociais. Barbarói, Santa Cruz, n. 38, p. 45-59, jan./jun. 2013. Disponível em: $<$ https://bit.ly/2QtXyVC $>$. Acesso em: 13 dez. 2018.

SANTAELLA, L. A crítica das mídias na entrada do século 21. In: PRADO, J. L. A. (Org.). Crítica das práticas midiáticas: da sociedade de massa às ciberculturas. São Paulo: Hacker, 2002, p. 44-56.

SANTAELLA, L. A pós-verdade é verdadeira ou falsa? Barueri: Estação das Letras e Cores, 2019.

SANTOS, E.; WEBER, A. Educação e cibercultura: aprendizagem ubíqua no currículo da disciplina didática. Revista Diálogo Educacional, Curitiba, v. 13, n. 38, p. 285-302, jan./abr. 2013. Disponível em: <https://bit.ly/2MQrvZt>. Acesso em: 20 set. 2018.

SANTOS, E.; COLACIQUE, R.; CARVALHO, F. S. P. A autoria visual na internet: o que dizem os memes? Quaestio, Sorocaba, v. 18, n. 1, p. 135-157, maio 2016. Disponível em: $<$ https://bit.ly/2MGandy>. Acesso em: 14 abr. 2019.

SILVEIRA, S. A. Concentração, modulação e desinformação nas redes. In: AZEVEDO, J. S. G.; POCHMANN, M. (Orgs.). Brasil: incertezas e submissão? São Paulo: Fundação Perseu Abramo, 2019, p. 27-44.

\footnotetext{
i Mestranda (bolsista FAPERJ) no Programa de Pós-Graduação em Educação, Cultura e Comunicação em Periferias Urbanas (PPGECC) da Universidade do Estado do Rio de Janeiro/Faculdade de Educação da Baixada Fluminense (UERJ/FEBF). E-mail: marcellemteixeira@gmail.com / Orcid: https://orcid.org/0000-0002-17992769

ii Doutor pelo Programa de Pós-Graduação em Educação (ProPEd) da Universidade do Estado do Rio de Janeiro (UERJ). Professor Adjunto da Faculdade de Educação da UERJ e do Programa de Pós-Graduação em Educação, Cultura e Comunicação em Periferias Urbanas (PPGECC) da Faculdade de Educação da Baixada Fluminense da UERJ. E-mail: junnior_2003@yahoo.com.br / Orcid: http://orcid.org/0000-0002-5221-7135

${ }^{\text {iii } U s o ~ d e ~ c o n t e ̂ i n e r e s ~ n o ~ B r a s i l ~ e m ~ t e m p o s ~ d e ~ p a n d e m i a . ~ D i s p o n i ́ v e l ~ e m: ~<h t t p s: / / i s . g d / O 5 t i C 7>. ~ A c e s s o ~ e m: ~} 7$ maio 2020.

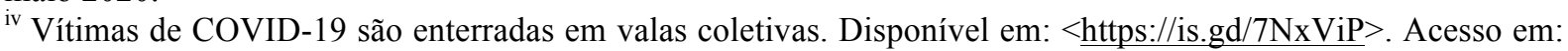
7 maio 2020.
} 


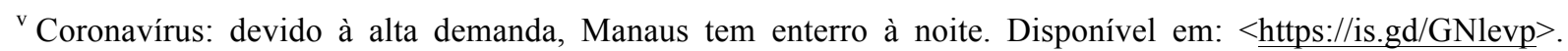
Acesso em: 7 maio 2020.

${ }_{\text {vi }}$ Estudos para decidir critérios de preferências para UTI. Disponível em: <https://is.gd/xjgNte>. Acesso em: 16 maio 2020.

vii “E daí? Lamento. Quer que eu faça o quê?', diz Bolsonaro sobre mortes por coronavírus. Disponível em: $<$ https://glo.bo/35E8iFc $>$. Acesso em: 7 maio 2020.

viii A primeira autora do texto vem realizando a pesquisa e conduzindo o trabalho de campo, enquanto o segundo autor do trabalho orienta a pesquisa em questão.

${ }^{\text {ix }}$ Moro alega que Bolsonaro busca interferir na Polícia Federal. Disponível em: $<$ https://is.gd/hf9dS3 $>$. Acesso em: 6 maio 2020.

${ }^{\mathrm{x}}$ Hashtag \#FechadoComBolsolnaro ultrapassa 78 mil tweets. Disponível em: $<$ https://is.gd/jkAZK9>. Acesso em: 6 maio 2020.

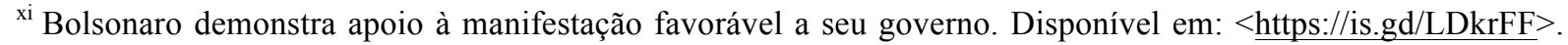
Acesso em: 17 maio 2020.

xii Balanço do número de infectados e mortos pelo novo coronavírus. Disponível em: $<$ https://is.gd/NVDclF $>$. Acesso em: 27 maio 2020.

xiii Mito vem sendo um adjetivo comumente atribuído ao presidente brasileiro por um grupo de pessoas que continuam apoiando os discursos e atos do governo.

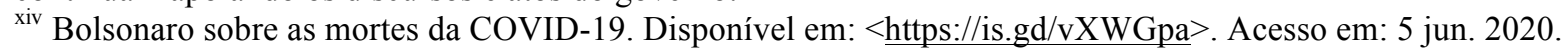

${ }^{\mathrm{xv}}$ Bolsonaro diz que não será uma "gripezinha" que irá derrubá-lo. Disponível em: $<$ https://is.gd/PWLPP0 $>$. Acesso em: 21 de abr. 2020.

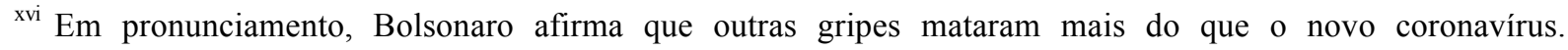
Disponível em: $<$ https://is.gd/MvPUGI $>$. Acesso em: 17 maio 2020.

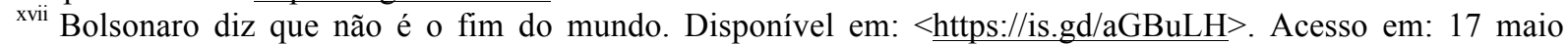
2020 .

xviii Bolsonaro afirma que estão superdimensionando o poder do coronavírus. Disponível em: $<$ https://is.gd/Oea8E1>. Acesso em: 21 de abr. 2020.

xix Jair Bolsonaro demite Henrique Mandetta, ministro da Saúde no Brasil. Disponível em: $<$ https://is.gd/Bk9IEd >. Acesso em: 5 jun. 2020.

${ }^{x x}$ Nelson Teich pede demissão do cargo de ministro da Saúde. Disponível em: $<$ https://is.gd/bQG874> . Acesso em: 5 jun. 2020. 